NASA/TM-2007-214698

\title{
SRG110 Stirling Generator Dynamic Simulator Vibration Test Results and Analysis Correlation
}

Edward J. Lewandowski

Sest, Inc., Middleburg Heights, Ohio

Vicente J. Suarez and Thomas W. Goodnight

Glenn Research Center, Cleveland, Ohio

John Callahan

Pagnotta Engineering, Exton, Pennsylvania 


\section{NASA STI Program . . . in Profile}

Since its founding, NASA has been dedicated to the advancement of aeronautics and space science. The NASA Scientific and Technical Information (STI) program plays a key part in helping NASA maintain this important role.

The NASA STI Program operates under the auspices of the Agency Chief Information Officer. It collects, organizes, provides for archiving, and disseminates NASA's STI. The NASA STI program provides access to the NASA Aeronautics and Space Database and its public interface, the NASA Technical Reports Server, thus providing one of the largest collections of aeronautical and space science STI in the world. Results are published in both non-NASA channels and by NASA in the NASA STI Report Series, which includes the following report types:

- TECHNICAL PUBLICATION. Reports of completed research or a major significant phase of research that present the results of NASA programs and include extensive data or theoretical analysis. Includes compilations of significant scientific and technical data and information deemed to be of continuing reference value. NASA counterpart of peer-reviewed formal professional papers but has less stringent limitations on manuscript length and extent of graphic presentations.

- TECHNICAL MEMORANDUM. Scientific and technical findings that are preliminary or of specialized interest, e.g., quick release reports, working papers, and bibliographies that contain minimal annotation. Does not contain extensive analysis.

- CONTRACTOR REPORT. Scientific and technical findings by NASA-sponsored contractors and grantees.
- CONFERENCE PUBLICATION. Collected papers from scientific and technical conferences, symposia, seminars, or other meetings sponsored or cosponsored by NASA.

- SPECIAL PUBLICATION. Scientific, technical, or historical information from NASA programs, projects, and missions, often concerned with subjects having substantial public interest.

- TECHNICAL TRANSLATION. Englishlanguage translations of foreign scientific and technical material pertinent to NASA's mission.

Specialized services also include creating custom thesauri, building customized databases, organizing and publishing research results.

For more information about the NASA STI program, see the following:

- Access the NASA STI program home page at http://www.sti.nasa.gov

- E-mail your question via the Internet to help@sti.nasa.gov

- Fax your question to the NASA STI Help Desk at 301-621-0134

- Telephone the NASA STI Help Desk at 301-621-0390

- Write to: NASA Center for AeroSpace Information (CASI) 7115 Standard Drive Hanover, MD 21076-1320 


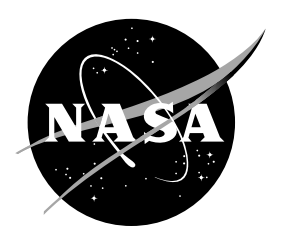

\section{SRG110 Stirling Generator Dynamic Simulator Vibration Test Results and Analysis Correlation}

Edward J. Lewandowski

Sest, Inc., Middleburg Heights, Ohio

Vicente J. Suarez and Thomas W. Goodnight

Glenn Research Center, Cleveland, Ohio

John Callahan

Pagnotta Engineering, Exton, Pennsylvania

Prepared for the

Fourth International Energy Conversion Engineering Conferenceand Exhibit (IECEC) sponsored by the American Institute of Aeronautics and Astronautics San Diego, California, June 26-29, 2006

National Aeronautics and

Space Administration

Glenn Research Center

Cleveland, Ohio 44135 


\section{Acknowledgments}

This work was enabled through the Department of Energy (DOE) 110-Watt Stirling Radioisotope Generator (SRG110) program and through NASA Science Mission Directorate Funding. Any opinions, findings, and conclusions or recommendations expressed in this article are those of the authors and do not necessarily reflect the view of the National Aeronautics and Space Administration. The authors thank Dennis Hill of Lockheed Martin Space Systems Company for his significant contributions, and Malcolm Robbie of Analex Corporation and Scott Cutlip of NASA Glenn Research Center for

their support designing and assembling the generator simulator. Sincere thanks are also extended to Dr. Kurng Chang of the Jet Propulsion Laboratory for guidance on force limiting and for support of testing. The authors also thank Tak Chan, Tony Kull, Robert Cockfield, and Dan Tantino of Lockheed Martin Space Systems Company, Rebecca Richardson of the DOE, and Jeffrey Schreiber and Richard Shaltens of NASA Glenn, for their counsel and support in preparing this paper.

This report is a formal draft or working paper, intended to solicit comments and ideas from a technical peer group.

This report contains preliminary findings, subject to revision as analysis proceeds.

Trade names and trademarks are used in this report for identification only. Their usage does not constitute an official endorsement, either expressed or implied, by the National Aeronautics and Space Administration.

Level of Review: This material has been technically reviewed by technical management.

Available from

NASA Center for Aerospace Information 7115 Standard Drive

Hanover, MD 21076-1320
National Technical Information Service 5285 Port Royal Road Springfield, VA 22161 


\title{
SRG110 Stirling Generator Dynamic Simulator Vibration Test Results and Analysis Correlation
}

\author{
Edward J. Lewandowski \\ Sest, Inc. \\ Middleburg Heights, Ohio 44130 \\ Vicente J. Suarez and Thomas W. Goodnight \\ National Aeronautics and Space Administration \\ Glenn Research Center \\ Cleveland, Ohio 44135 \\ John Callahan \\ Pagnotta Engineering \\ Exton, Pennsylvania 19341
}

\begin{abstract}
The U.S. Department of Energy (DOE), Lockheed Martin (LM), and NASA Glenn Research Center (GRC) have been developing the Stirling Radioisotope Generator (SRG110) for use as a power system for space science missions. The launch environment enveloping potential missions results in a random input spectrum that is significantly higher than historical radioisotope power system (RPS) launch levels and is a challenge for designers. Analysis presented in prior work predicted that tailoring the compliance at the generator-spacecraft interface reduced the dynamic response of the system thereby allowing higher launch load input levels and expanding the range of potential generator missions. To confirm analytical predictions, a dynamic simulator representing the generator structure, Stirling convertors and heat sources were designed and built for testing with and without a compliant interface. Finite element analysis was performed to guide the generator simulator and compliant interface design so that test modes and frequencies were representative of the SRG110 generator. This paper presents the dynamic simulator design, the test setup and methodology, test article modes and frequencies and dynamic responses, and post-test analysis results. With the compliant interface, component responses to an input environment exceeding the SRG110 qualification level spectrum were all within design allowables. Post-test analysis included finite element model tuning to match test frequencies and random response analysis using the test input spectrum. Analytical results were in good overall agreement with the test results and confirmed previous predictions that the SRG110 power system may be considered for a broad range of potential missions, including those with demanding launch environments.
\end{abstract}

\section{Introduction}

The Department of Energy (DOE), Lockheed Martin (LM), and NASA Glenn Research Center (GRC) undertook development of a high-efficiency, nominal 110-We (watts electric) Stirling Radioisotope Generator (SRG110) for use on Space Science Missions. Potential missions requiring radioisotope power systems include deep space missions and planetary surface missions involving stationary landers or rovers. LM, under contract to the DOE, is the System Integration Contractor for the SRG110.

The SRG110 was designed to produce at least 112 We at beginning-of-mission (BOM), using two opposed Stirling convertors and two Step 2 General Purpose Heat Source (GPHS) modules. The system efficiency is projected to be 22 to 25 percent with a system mass of less than $34 \mathrm{~kg}$. The SRG110 system efficiency would reduce the amount of radioisotope required by a factor of four or more compared to Radioisotope Thermoelectric Generators (RTGs). Infinia developed the Stirling convertors, and NASA GRC provided resources and expertise, development activities, analysis and testing.

The evolution of the SRG110 design, with the improvement of the Stirling convertor mounting arrangement and the development of a compliant launch interface, is discussed in detail in reference 1. A finite element model (FEM) of the SRG110 system containing detailed representations of the Stirling convertors was used to determine the response of critical components to the launch environment. Significant reductions in the dynamic response of the Stirling convertors to launch loading were realized through the use of a compliant launch adapter. The SRG110 and launch interface are depicted in figure 1. The spacecraft launch interface, similar to those used in past GPHS RTG 
missions was designed to achieve fundamental generator axial and lateral modes between 35 and $50 \mathrm{~Hz}$ for input vibration attenuation. The interface attaches to the spacecraft at the four locations near its outer diameter. Fundamentally, the interface is composed of two thin plates separated by a short distance to achieve the proper combination of axial and lateral stiffness. The SRG110 attaches at eight points - four points on the same plate as the spacecraft interface and four points on the second plate offset along the axis of the SRG110. The Stirling convertors are joined with an interconnect tube at their pressure vessels and are fastened to the generator housing at their cold flanges (depicted in blue in fig. 1). The interconnect tube stabilized the Stirling convertors so that individual Stirling convertor

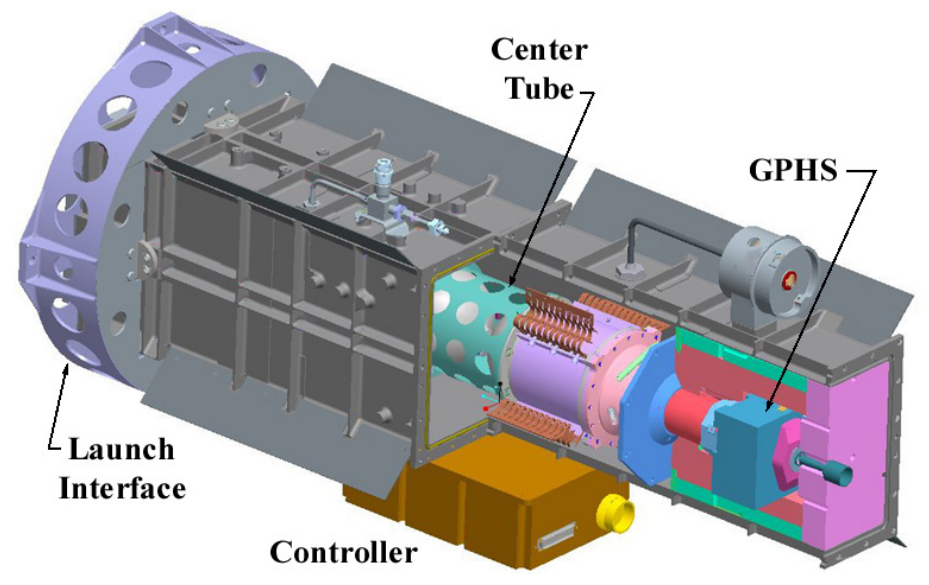

Figure 1.-Component mounting in the SRG110 generator and launch interface.

vibration modes were combined into one higher frequency mode and simplified the Stirling convertor mounting arrangement (ref. 1). One General Purpose Heat Source (GPHS) is preloaded in compression against each Stirling convertor heat collector. The controller is mounted on the side of the generator housing.

In anticipation of potential SRG110 engineering unit (EU) vibration testing, an SRG110 generator dynamic simulator was designed, built, and tested at NASA GRC. This reduced the risk involved with EU generator testing by validating the analytical model predictions of generator and Stirling convertor responses, validating the isolation adapter approach to lowering generator/Stirling convertor responses by test, and validating the interconnect tube mounting approach and loading on the Stirling convertors. The dynamic simulator test article, test results, and post test analysis will be described in the following sections.

\section{Test Article}

The generator dynamic simulator was designed and built by NASA GRC using Stirling convertor mass simulators. The Stirling convertor mass simulators were fastened to an interconnect tube that functioned as both an interconnect tube and a common pressure vessel, as shown in figure 2. The Stirling convertors were pressurized but not operated during the test. Since the focus of the test was on the system's response to external excitation, it was not necessary to use operating convertors. A two-piece cylindrical generator housing was designed to achieve a bending stiffness similar to that of the SGR110 housing. The mass models were instrumented and mounted inside the generator housing. Instrumented GPHS mass simulators were mounted on the Stirling convertor heater heads. Replicas of the preload stud and preload washer assembly and end covers were fabricated and installed to achieve proper compressive load on the GPHS mass simulators.

As depicted in figure 3, the test article was designed for testing in two configurations-hard-mounted and isolationmounted. The hard-mounted configuration used a cantilever base mount fixture to simulate the SRG110 attached to a stiff spacecraft interface. The frequency goal for the fundamental bending mode of this test configuration was greater than $100 \mathrm{~Hz}$. The isolation-mounted configuration simulated the SRG110 attached to the spacecraft through the compliant launch interface. Stiffness of the flight interface was simulated by a set of nine flexures as shown in figure 3(b).

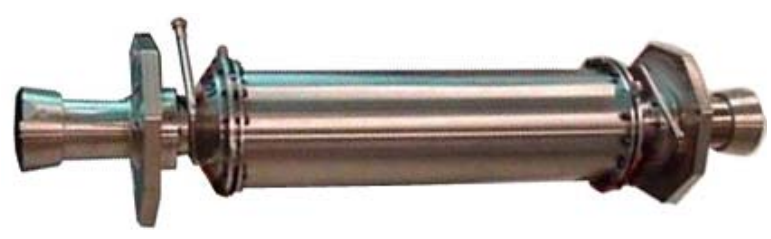

Figure 2.-Stirling convertors joined at alternators by interconnect tube.

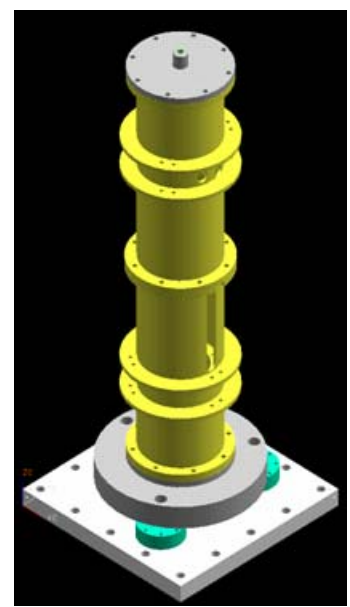

(a)

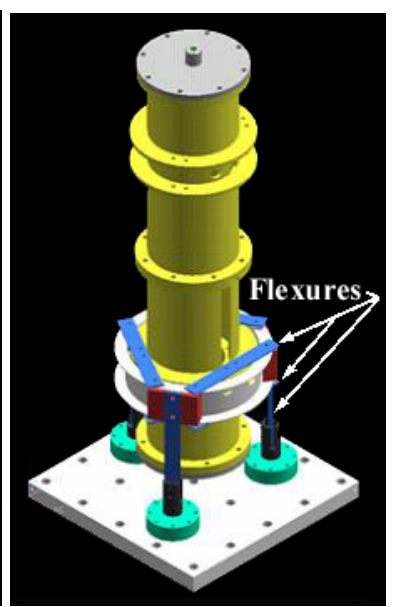

(b)
Figure 3.- - Hard mount a) and isolation-mount (b) test configurations. 
The flexure arrangement allowed somewhat independent adjustment of lateral and axial frequencies. The stiffness of the three flexures parallel to the simulator axis primarily determined the frequency of the fundamental lateral modes. The stiffness of two sets of three flexures perpendicular to the simulator axis largely controlled the frequency of the fundamental axial mode. The frequency goal for the isolation-mount's fundamental axial and lateral modes was between 35 and $50 \mathrm{~Hz}$.

\section{Test Setup and Dynamic Environments}

Vibration testing was performed at the NASA GRC Structural Dynamics Laboratory (SDL). Tests were performed parallel to the axis of the dynamic simulator (Z-axis) and perpendicular to the axis of the simulator (X-axis). The dynamic simulator-either hard-mounted or isolation-mounted-was attached to the test plate at three locations. Three force transducers, one at each attachment location, measured the axial and lateral interface forces during testing (see fig. 3). A total of 97 channels (93 acceleration, 3 force, and 1 internal pressure) of data were acquired simultaneously. Two control accelerometers were mounted oriented in the direction of motion on opposite sides of the aluminum test plate. The average of the two control accelerometer signals was used to control the electrodynamic shaker input.

Multiple level random vibration tests were performed on the Stirling Generator Dynamic Simulator. Consistent with previous test efforts (refs. 1 and 2), the random

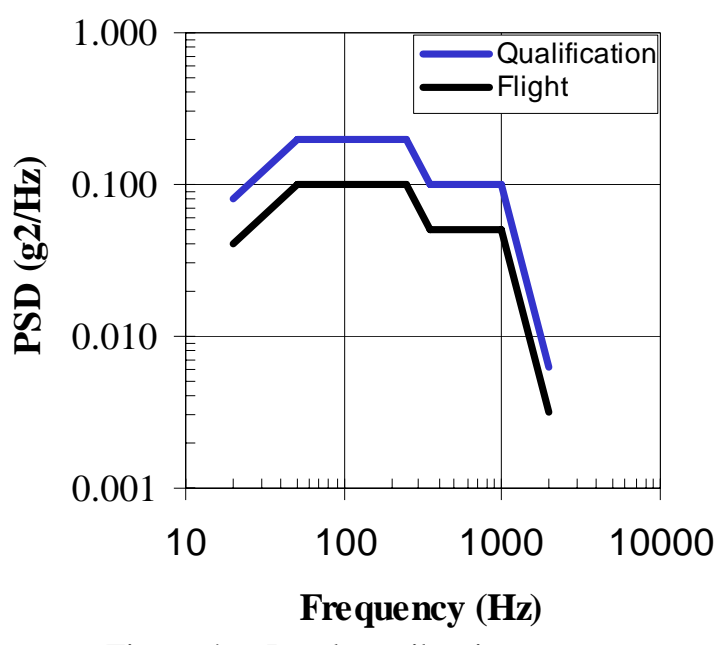

Figure 4.-Random vibration spectra. vibration test spectrum applied was a slightly modified version of the RPS flight acceptance test profile shown in figure 4. The flight level input was 8.7 grms and the qualification (flight $+3 \mathrm{~dB}$ ) level input was 12.4 grms. The highest input level applied was flight $+4.8 \mathrm{~dB}$, which was 15.1 grms (peak input $0.3 \mathrm{~g} / \mathrm{Hz}$ ). Force limiting was employed using the interface force transducer measurements per reference 3. Sinusoidal resonance surveys were conducted prior to and following random vibration tests to verify that no structural changes occurred as a result of random vibration testing.

\section{Test Article Modal Results}

Modes and frequencies were extracted from test data at the lowest level of random vibration input, flight level $-12 \mathrm{~dB}$. At low level, the data quality was at its highest, and localized nonlinearities were minimized. Test display models (TDMs), simplified models of the basic geometry of the test articles, were created to visualize the mode shapes obtained from the mode curve fitting analysis. The TDM was based on a centerline average of all accelerometers at each station along the length of the test article. The averaged acceleration was calculated in the time domain and then post processed to the frequency domain for mode extraction. Figure 5 shows the first two modes of the isolation-mounted test article. In the figure, the Stirling convertor responses are represented in blue and the housing response in green. The first lateral mode was typical of a cantilever-mounted structure and was similar to the SRG110 first lateral mode. The predominant motion of the simulator in the second mode was at its inboard end.

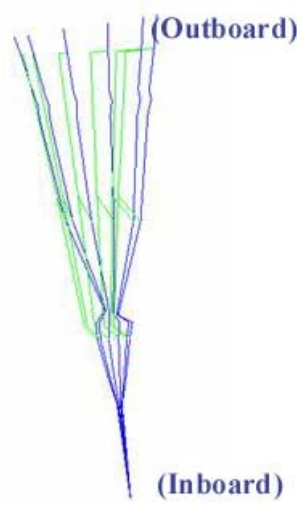

(a)

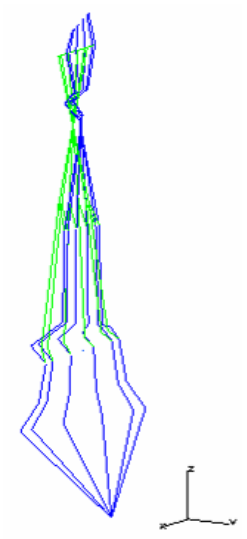

(b)

Figure 5.--Isolation-mounted test article first (a) and second (b) mode shapes.

\section{Analytical Models and Model Tuning}

Finite element models (FEMs) of the hard-mounted and isolation-mounted configuration were created concurrent with the design of the test articles. Both models were tuned after the test to match the test modes and frequencies. Table 1 shows a comparison of the measured modes and frequencies to results given by the FEM after tuning. The stiffness of the lateral flexures was tuned to the frequency of the first lateral mode, but there remained 
TABLE 1.-COMPARISON OF TEST AND ANALYTICAL MODES AND FREQUENCIES

\begin{tabular}{|l|c|c|c|c|}
\hline \multirow{2}{*}{\multicolumn{2}{c|}{ Mode }} & \multicolumn{4}{|c|}{ Natural frequency (Hz) } \\
\cline { 2 - 5 } & \multicolumn{2}{|c|}{$\begin{array}{c}\text { Isolation- } \\
\text { mounted } \\
\text { configuration }\end{array}$} & \multicolumn{2}{|c|}{$\begin{array}{c}\text { Hard-mounted } \\
\text { configuration }\end{array}$} \\
\cline { 2 - 5 } & Test & $\begin{array}{c}\text { Tuned } \\
\text { model }\end{array}$ & Test & $\begin{array}{r}\text { Tuned } \\
\text { model }\end{array}$ \\
\hline Lateral 1st bending & 31.6 & 31.6 & 89.4 & 89.4 \\
\hline Lateral 2nd bending & 81.2 & 70.0 & \multirow{2}{*}{------------------ } \\
\hline Longitudinal translation & 43.5 & 43.0 & ------------------ \\
\hline
\end{tabular}

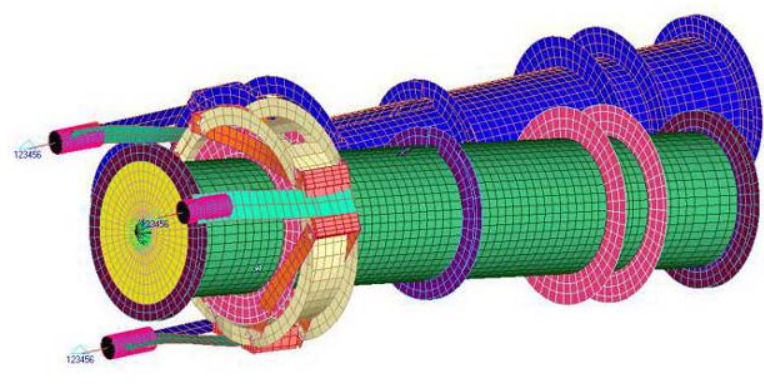

(a)

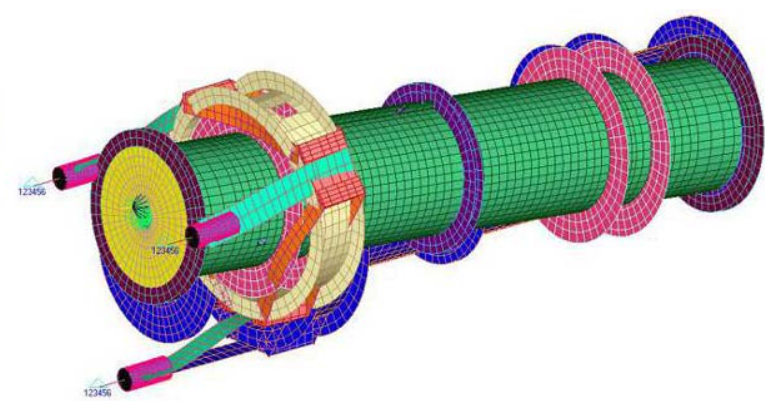

(b)

Figure 6.-First (a) and Second (b) lateral modes of the SRG110 dynamic simulator.

some difference between the test and analytical frequencies of the second lateral mode. The analytical mode shapes for both the first and second lateral modes (fig. 6) and the longitudinal mode were in good agreement with the mode shapes measured by test. As shown in the figure, the second mode was a flexure bending mode- the SRG110 on the compliant launch interface (fig. 1) does not have a similar mode. No longitudinal mode was measured for the hardmounted configuration because available test time allowed for testing in the lateral (X-axis) direction only.

\section{Vibration Test Results}

Due to the relatively high amplification of the test article, hard-mounted random vibration tests were limited to flight level $-12 \mathrm{~dB}$ (fig. 4) in order not to exceed previously set response limits. Conversely, amplification of the isolation-mounted test article was low, so this configuration was tested to $+4.8 \mathrm{~dB}$ (15.1 grms, $0.3 \mathrm{~g}^{2} / \mathrm{Hz}$ maximum) above the random vibration flight level. This corresponds to the highest level of vibration anticipated for RPS.

Linearity studies were performed on both test articles. The variation of modal frequencies with lateral vibration level for the hard-mounted and isolationmounted test article are shown in figure 7. No significant change in fundamental lateral frequency was observed for the hard-mounted configuration over the relatively small range of vibration input. Slight local nonlinearities were observed at higher input levels for both first and second $\mathrm{X}$-axis bending modes

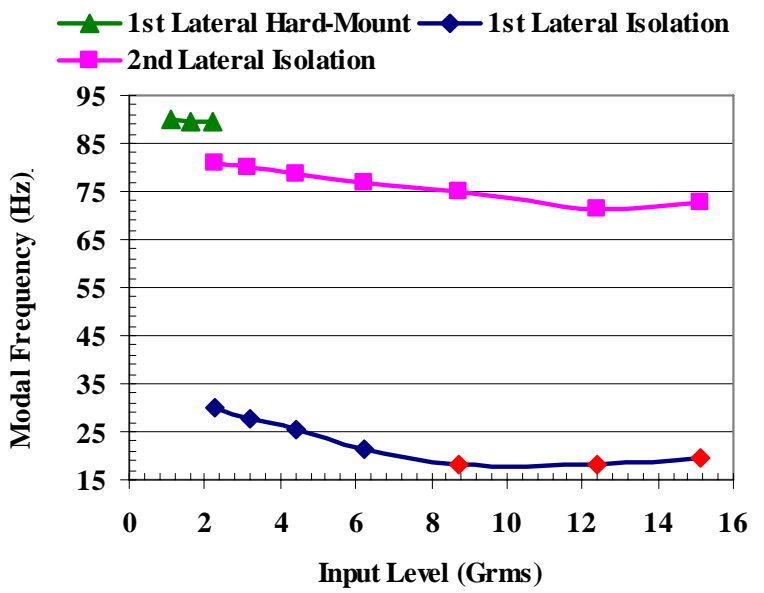

Figure 7.-First and second isolation-mount structure modal frequency variation with lateral vibration. for the isolation-mounted configuration. These nonlinearities are likely attributed to characteristics of the Stirling Generator Dynamic Simulator and would not be expected in the actual flight hardware. Figure 7 shows three points (depicted in red) where the first bending mode shifted below $20 \mathrm{~Hz}$. Since the random test input energy was applied only from 20 to $2000 \mathrm{~Hz}$, mode frequency 
extraction below $20 \mathrm{~Hz}$ has some uncertainty due to the variation in applied energy below $20 \mathrm{~Hz}$ and filtering effects.

Damping of the first two lateral modes of the isolation-mounted structure also varied with input level. Figure 8 shows the outboard GPHS response divided by the input for the range of inputs applied. As the input level was increased the frequency of both modes shifted downward, and the first mode became significantly less pronounced. This was largely attributed to an increase in the structural damping of the test unit. Since the fundamental mode was so highly damped at the highest vibration input levels, the second bending mode frequency was used for the force limiting breakpoint.

The response of the hard-mounted structure is compared with that of the isolation-mounted test article in figure 9 as a ratio of component responses to component allowables. Here, for purposes of an even comparison, the hard-mounted responses were scaled from $1 / 4$ flight level to full flight level. Ratios larger than 1 indicate that the response would exceed the component allowable. All flight level hardmounted responses would have exceeded the component allowables - this was the reason for limiting the input to $1 / 4$ flight level. In contrast, component responses in the isolation-mounted test configuration were all within the component allowables. Indeed, even at the highest anticipated launch loading (flight $+4.8 \mathrm{~dB}$ ), component responses in the isolation-mounted test article were within their respective allowables. It is of interest to compare the trends in the component responses (displayed from left to right from the inboard end to the outboard end) arising from the two mounting arrangements. Hard-

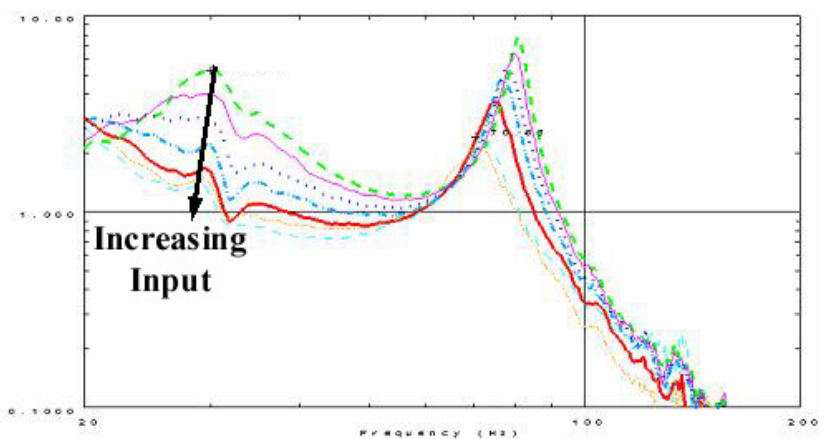

Figure 8.-Variation of isolation-mount structure first and second modes with lateral vibration input level.

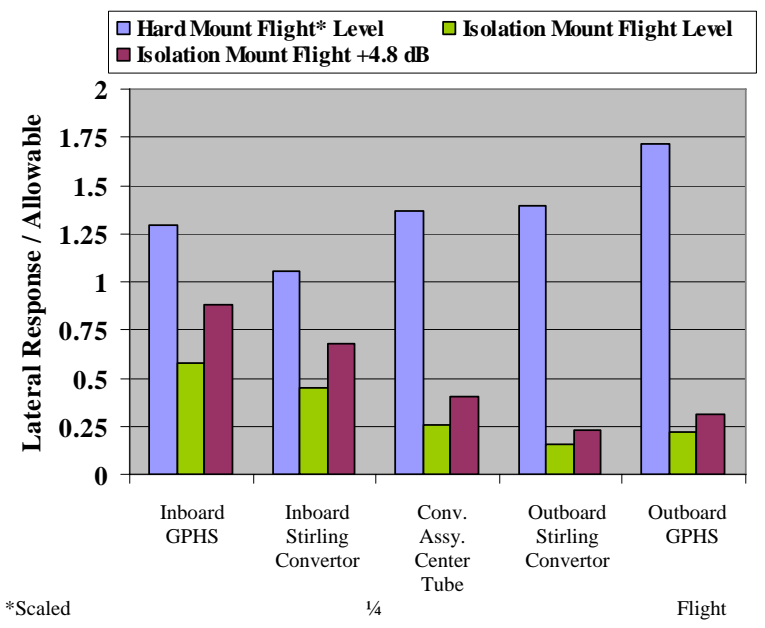

Figure 9.- - Lateral response of the test article hard mounted and isolation-mounted.

mounted responses were dominated by the first cantilever mode of the structure where outboard accelerations are the most significant. Conversely, the isolation-mounted test article responses were dominated by the structure's second mode where the inboard end had the highest accelerations. Thus, hard-mounted component response levels increased from the inboard end to the outboard end while isolation-mounted responses decreased from the inboard end to the outboard end.

\section{Test and Analysis Correlation}

Random response analysis was performed with both hard-mounted and isolation-mounted FEMs. The analysis included force limiting per reference 3, consistent with force limiting imposed during the test. Since the first lateral mode of the isolation-mounted configuration was highly damped and the second lateral mode had a higher response, the roll off frequency on the force limiting curve was imposed at the second lateral mode for test-the analysis imposed force limiting in the same manner. Five percent structural damping was assumed for all analytical modes.

Figure 10 shows a comparison of the test and analysis responses to lateral vibration input for both the hardmounted configuration and the isolation-mounted configuration. The results displayed good general agreement in the magnitude of responses as well as indicating the same trends in component response levels from the inboard end to the outboard end. The largest difference between test and analysis results for the isolation-mounted structure was at the outboard end. This was primarily due to the response of the first mode where the outboard component responses are the highest. The first mode was highly damped in the test, but the analysis was performed using 5 percent damping and thus the analytical responses are higher than those of the test. The influence of damping was 
1/4 Flight Level Lateral Input Hard Mount

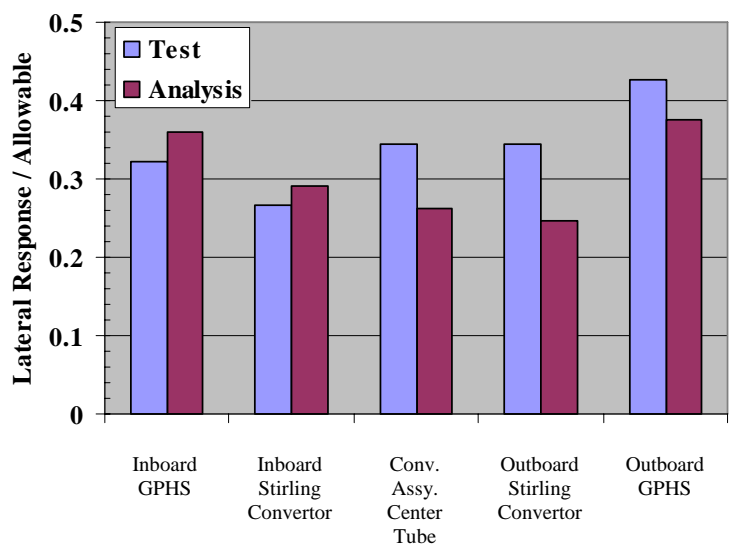

(a)

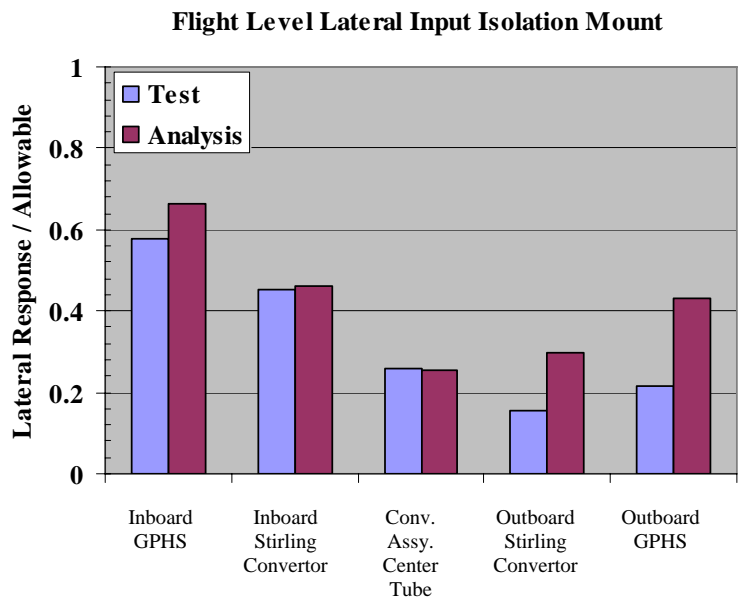

(b)

Figure 10.-Test and analytical lateral response of the test article in hard-mounted

(a) and isolation-mounted (b) configurations.

clear on the inboard GPHS, which was closest to the inboard mounting point. The first mode at $32 \mathrm{~Hz}$ was not evident in the test data shown in figure 11, but can be seen in the analysis results. For both analysis and test, the second mode at $81 \mathrm{~Hz}$ had the highest response. Again for the second mode, the test article had higher damping than the 5 percent damping used in the analysis, as indicated by the broader peak in the test curve and the higher response in the analysis curve. The peak at $200 \mathrm{~Hz}$ for the analysis and $300 \mathrm{~Hz}$ for the test was the response due to the Stirling convertor heater head bending mode. The difference in frequency was primarily due to the fact that only the stiffness of the heater head outer shell was represented in the FEM. Heater head lateral load test results reported subsequent to the analysis effort indicate that the heater head internal structure makes a significant contribution to the overall heater head stiffness.

Comparison of the test and analysis responses to axial vibration input for the isolation-mounted configuration is shown in figure 12. There was again good agreement between test and analysis. In the axial direction, the response of all components was similar, and well below the component allowables. The reason for the similarity can be explained by examining figure 13, which is representative of all the component responses. The primary response in the axial direction was due to the first mode at $44 \mathrm{~Hz}$, which was controlled by the stiffness of the flexures mounted perpendicular to the axis of the test article. The test article itself was very stiff in the axial direction, and only one other mode was evident in the analytical results below $400 \mathrm{~Hz}$. Then the dominant response was the fundamental axial mode due to the isolation flexures, where the test article moves together as a rigid body, and thus all component responses are the same. The low frequency fundamental mode acts as a low bandpass filter so that the response rolls off with increasing frequency and the resulting acceleration levels are low. 


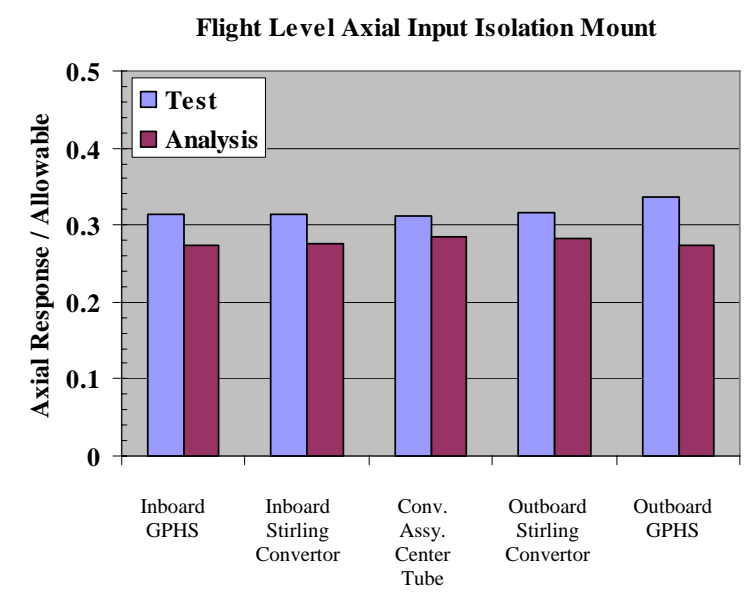

Figure 12.- Test and analytical axial response of the test article in isolation-mounted test configuration.

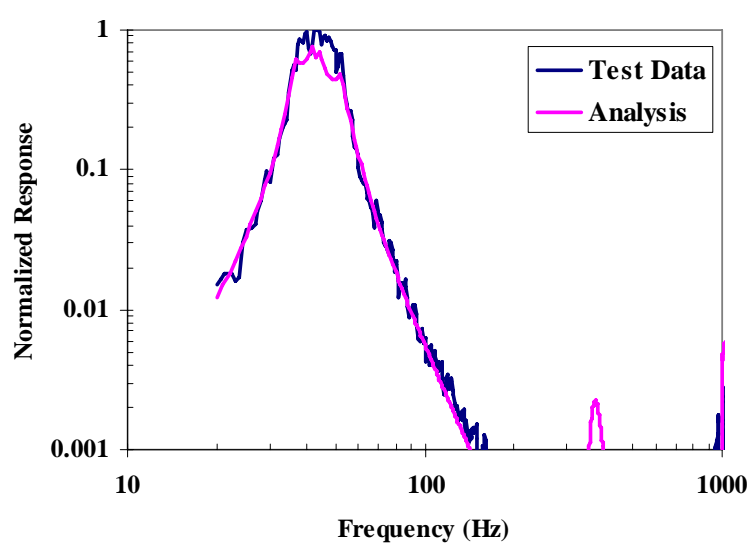

Figure 13.-Axial response of the outboard Stirling convertor to flight level vibration input in the isolation-mounted test configuration.

\section{Conclusion}

The generator simulator test served as an excellent pathfinder for the SRG110 EU. Connecting the Stirling convertors together into one subassembly simplified the load path and eliminated individual Stirling convertor modes. Accurate representations of the GPHS preload and support hardware maintained the intended preload between the GPHS simulators and the Stirling convertor heat collectors, even at the highest input levels. In addition, experience gained with interface force measurement hardware, force limiting test methodology, and testing at full RPS qualification level will be of great benefit to future testing of the SRG110 generator hardware.

Overall agreement between the test and analytical results was very good. The FEMs were tuned such that the fundamental structural modes were within $1 \mathrm{~Hz}$ of the test frequencies. The method of employing analytical force limiting was a good representation of the implementation in test. The analysis assumed 5 percent damping, which on average was a reasonable estimate of the test hardware damping. Analytical component responses displayed the same overall levels and trends as the test data. The correlation between analysis and test adds confidence that analytical predictions of the SRG110 responses are valid.

As demonstrated in this test, isolation mounting at the spacecraft interface is a viable method to reduce the vibration response of the generator and its components. Response levels with isolation mounting were 2 to 9 times lower than the hard-mounted configuration. For the isolation configuration tested, force limiting was rolled off at the frequency of the second lateral mode $(81 \mathrm{~Hz})$ because its response was the most pronounced. The second mode response was an artifact of the flexure configuration and this type of mode is not expected in the SRG110 isolation interface. Force limiting rolled off below $50 \mathrm{~Hz}$ would be expected to result in larger attenuation of the vibration input. The Stirling generator dynamic simulator test demonstrated that a structure representative of the EU generator could be mounted on a spacecraft adapter that was tuned to provide isolation, and tested to the highest RPS qualification input levels (15.1 grms, $0.3 \mathrm{~g}^{2} / \mathrm{Hz}$ maximum) such that all component responses, including the Stirling convertors, were within their respective component qualification allowables.

\section{References}

1. Hill, D.H., Goodnight, T.W., Suárez, V.J., Lewandowski, E.J., Qui, S., Callahan, J., Richardson, R., "Dynamic Characterization of STC Stirling Convertor and Improved Mechanical Integration in SRG110 Power System,” in Proceedings of the 3rd International Energy Conversion Engineering Conference, AIAA-2005-5746, AIAA, Reston, VA, 2005.

2. Goodnight, T.W., Hughes W.O., and McNelis, M.E., "Dynamic Capability of an Operating Stirling Convertor," in Proceedings of the 35th Intersociety Energy Conversion Engineering Conference, Las Vegas, NV, July 2428, 2000, NASA/TM-2000-210527, AIAA-2000-2839.

3. Scharton, T., "Force Limited Vibration Testing," NASA Technical Handbook NASA-HDBK-7004, January 2003. 


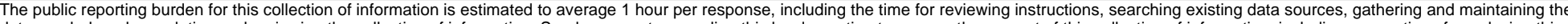

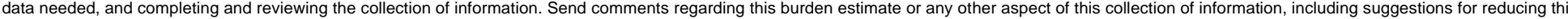

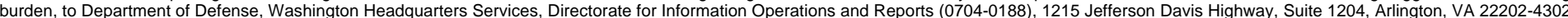

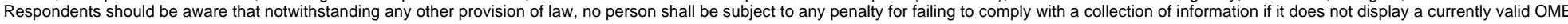
control number.

PLEASE DO NOT RETURN YOUR FORM TO THE ABOVE ADDRESS.

\section{REPORT DATE (DD-MM- $Y Y Y Y)$ \\ 2. REPORT TYPE \\ 3. DATES COVERED (From - To)}

01-12-2007

\section{TITLE AND SUBTITLE}

SRG110 Stirling Generator Dynamic Simulator Vibration Test Results and Analysis

Correlation

Technical Memorandum

\section{AUTHOR(S)}

Lewandowski, Edward, J.; Suarez, Vicente, J.; Goodnight, Thomas, W.; Callahan, John

\section{5a. CONTRACT NUMBER}

5b. GRANT NUMBER

5c. PROGRAM ELEMENT NUMBER

5d. PROJECT NUMBER

5e. TASK NUMBER

5f. WORK UNIT NUMBER

WBS 22-972-20-01

8. PERFORMING ORGANIZATION

REPORT NUMBER

E-15899

National Aeronautics and Space Administration

John H. Glenn Research Center at Lewis Field

Cleveland, Ohio 44135-3191

9. SPONSORING/MONITORING AGENCY NAME(S) AND ADDRESS(ES)

National Aeronautics and Space Administration

Washington, DC 20546-0001

\section{SPONSORING/MONITORS ACRONYM(S) \\ NASA \\ 11. SPONSORING/MONITORING REPORT NUMBER \\ NASA/TM-2007-214698; AIAA-2006- 4063}

\section{DISTRIBUTION/AVAILABILITY STATEMENT}

Unclassified-Unlimited

Subject Category: 39

Available electronically at http://gltrs.grc.nasa.gov

This publication is available from the NASA Center for AeroSpace Information, 301-621-0390

\section{SUPPLEMENTARY NOTES}

\section{ABSTRACT}

The U.S. Department of Energy (DOE), Lockheed Martin (LM), and NASA Glenn Research Center (GRC) have been developing the Stirling Radioisotope Generator (SRG110) for use as a power system for space science missions. The launch environment enveloping potential missions results in a random input spectrum that is significantly higher than historical radioisotope power system (RPS) launch levels and is a challenge for designers. Analysis presented in prior work predicted that tailoring the compliance at the generator-spacecraft interface reduced the dynamic response of the system thereby allowing higher launch load input levels and expanding the range of potential generator missions. To confirm analytical predictions, a dynamic simulator representing the generator structure, Stirling convertors and heat sources were designed and built for testing with and without a compliant interface. Finite element analysis was performed to guide the generator simulator and compliant interface design so that test modes and frequencies were representative of the SRG110 generator. This paper presents the dynamic simulator design, the test setup and methodology, test article modes and frequencies and dynamic responses, and post-test analysis results. With the compliant interface, component responses to an input environment exceeding the SRG110 qualification level spectrum were all within design allowables. Post-test analysis included finite element model tuning to match test frequencies and random response analysis using the test input spectrum. Analytical results were in good overall agreement with the test results and confirmed previous predictions that the SRG110 power system may be considered for a broad range of potential missions, including those with demanding launch environments.

\section{SUBJECT TERMS}

Dynamic structural analysis; Dynamic models; Vibration isolators; Resonant frequencies; Dynamic response; Stirling cycle; Electric generators

\begin{tabular}{|c|c|c|c|c|}
\hline \multicolumn{3}{|c|}{ 16. SECURITY CLASSIFICATION OF: } & \multirow{2}{*}{$\begin{array}{l}\text { 17. LIMITATION OF } \\
\text { ABSTRACT } \\
\text { UU }\end{array}$} & \multirow{2}{*}{$\begin{array}{l}\text { 18. NUMBER } \\
\text { OF } \\
\text { PAGES } \\
13\end{array}$} \\
\hline $\begin{array}{l}\text { a. REPORT } \\
\mathrm{U}\end{array}$ & $\begin{array}{l}\text { b. ABSTRACT } \\
U\end{array}$ & $\begin{array}{l}\text { c. THIS } \\
\text { PAGE } \\
\text { U }\end{array}$ & & \\
\hline
\end{tabular}

19a. NAME OF RESPONSIBLE PERSON STI Help Desk (email:help@sti.nasa.gov) 19b. TELEPHONE NUMBER (include area code) 301-621-0390 

